\title{
Que história é essa? Que barulho é esse? Uma introdução ao debate sobre a Antropologia Histórica e a História Cultural
}

Maria Fátima Roberto Machado ${ }^{1}$ Universidade Federal de Mato Grosso

Resumo: Este artigo é uma introdução ao debate entre a Antropologia e História nas abordagens voltadas para o estudo das culturas. Baseada na perspectiva de Pierre Bourdieu sobre a definição do campo científico, é uma introdução às relações entre as duas disciplinas em termos mais gerais e especificamente na historiografia francesa, oferecendo ainda um panorama acerca da expressão desse debate em nossa universidade, a UFMT, a partir das pesquisas da antropóloga Denise Maldi, uma pioneira nos estudos aplicados à Etnohistória da fronteira Oeste do Brasil colonial.

Palavras-chave: antropologia histórica; história cultural; etnohistória; Mato Grosso; século XVIII. 


\title{
What story is that? What is that noise? An introduction to the debate on Historical Anthropology and Cultural History
}

\begin{abstract}
This paper assesses the current debates about the relationship between Historical Anthropology and Cultural History as co-related disciplines. Based on Pierre Bourdieu's perspective of scientific field, it is an introduction to the disputes and alliances between both disciplines, in general and particularly boundaring contemporary French Cultural History, also offering a basic view of some studies produced at our University, the UFMT, through the research of a pioneer anthropologist Denise Maldi, about the Indians of the Brazilian West frontier in the XVIII century.
\end{abstract}

Keywords: historical anthropology; cultural history; ethnic history; Mato Grosso; XVIII century.

\section{¿De qué estás hablando? ¿Qué bulla es esa? Introducción al debate sobre Antropología Histórica e Historia Cultural}

Resumen: Este artículo es una introducción al debate entre Antropología e Historia en los enfoques centrados en el estudio de las culturas. Partiendo de la perspectiva de Pierre Bourdieu sobre la definición del campo científico, se trata de una introducción a las relaciones entre las dos disciplinas en términos más generales y concretamente en la historiografía francesa, ofreciendo además una panorámica de la expresión de este debate en nuestra universidad, la UFMT, basado en la investigación de la antropóloga Denise Maldi, pionera en estudios aplicados a la Etnohistoria de la frontera occidental del Brasil colonial.

Palabras clave: antropología histórica; historia cultural; etnohistoria; Mato Grosso; siglo XVIII. 


\section{Prólogo: introdução ao dossiê Mato Grosso português - Ensaios de Antropologia Histórica ${ }^{2}$}

Os trabalhos que tenho aqui o prazer de apresentar foram produzidos para o primeiro curso de especialização em Antropologia da UFMT (1999-2000) e reúnem um grupo de estudantes interessados em uma abordagem etnográfica da história de Mato Grosso e do Amazonas, em especial relacionada ao universo de representações dos portugueses colonizadores do século XVIII, buscando enfocar de modo renovado velhos objetos, tais como o alargamento das fronteiras com a Espanha, o povoamento, a exploração econômica colonial e o relacionamento com os povos indígenas.

Trata-se, bem ao sabor dos novos tempos, de experimentos. São olhares lançados sobre uma história que até as últimas décadas contentou se em ser "regional", factual, alvo quase exclusivo de uma historiografia comprometida com as metanarrativas da história econômica, onde Mato Grosso era só um território longínquo e desconhecido, rico em ouro e infestado de índios. Foi preciso que a chamada crise dos paradigmas atingisse também os nossos pesquisadores, para que uma nova geração de estudantes demandasse os cursos de pós-graduação e começasse a produzir o que se convencionou chamar de "nova" História, mais aberta ao diálogo com a Antropologia, facilitando a que este experimento encontrasse seu caminho.

Caminhos, trajetos, trajetórias que acabaram por agregar esse grupo de pessoas, de pesquisadores, para pensar Mato Grosso em uma perspectiva renovada, interessada não tanto no resgate da importância da mão-de-obra indígena para a manutenção do sistema colonial brasileiro, e mais em interpretar as representações portuguesas que foram frutos de embates e confrontos culturais. Cultura e história entrecruzam-se, emaranham-se nas relações étnicas, resultando em alianças e conflitos, esses sim vitais para a manutenção do empreendimento português na fronteira, pós-tratado de Santo Ildefonso. A este respeito, as fontes privilegiadas são as coleções de relatos escritos pelos portugueses - exploradores, administradores, demarcadores de limites, militares - que aqui estiveram temporariamente a mando da Coroa, e que se envolveram com os índios por dever de ofício, por empatia ou até mesmo profunda curiosidade.

Os relatos portugueses coloniais fornecem aos pesquisadores abundantes recursos etnográficos para a abordagem e desenvolvimento de uma multiplicidade de temas e objetos, que hoje são reconhecidos como pertinentes tanto ao campo da "nova" Antropologia quanto da "nova" História. No interior da colônia, nas águas do outrora pestilento Guaporé, portugueses iluministas construíram fortes e plantaram cidades em territórios até então unicamente indígenas. Guiados pela política pombalina, esses portugueses foram bastante empenhados na construção de aldeamentos - como o de Albuquerque, para os índios Guaná, que deu origem à cidade de Corumbá, um dos mais importantes polos urbanos de Mato Grosso

\footnotetext{
${ }^{2} \mathrm{O}$ artigo da professora Maria Fátima Roberto Machado, "Que história é essa? Que barulho é esse? Uma introdução ao debate sobre a Antropologia Histórica e a História Cultural”, é parte integrante do dossiê Mato Grosso Português: ensaios de Antropologia Histórica, publicado originalmente pela Editora da UFMT, em 2002, no volume 6 da Série Antropologia, publicação do Departamento de Antropologia, que a Aceno tem reeditado em suas últimas edições. Como Maria Fátima é organizadora do dossiê e autora do primeiro artigo do referido volume, optamos por publicar nesta reedição a introdução ao dossiê, em que ela apresenta os seis artigos que o compõem. Os outros cinco artigos do dossiê Mato Grosso Português: ensaios de Antropologia Histórica serão publicados nas edições seguintes da Aceno, na ordem em que estão publicados na primeira publicação. Toda essa reedição de artigos da Série Antropologia está sendo realizada com autorização da Editora da UFMT, detentora dos direitos autorais.
} 
do Sul - no estabelecimento de relações "pacíficas" com os grupos indígenas que dificultavam a árdua missão de expandir e consolidar a fronteira Oeste do Brasil.

A lei do Diretório dos Índios era o documento que regulamentava as suas relações com o colonizador, vigente entre os anos de 1757 e 1798, voltada para a domesticação e disciplinarização dos "habitantes naturais" da terra, através da sedentarização e da evangelização - pós-jesuítica - na busca de soluções para os graves problemas de definição dos limites do território lusitano e do seu povoamento. Era um instrumento jurídico de política colonial, que propunha uma nova ordem social, regulamentada pela exclusividade do uso da língua portuguesa, desautorizando definitivamente a língua geral falada em toda a colônia, pelo convívio das populações em povoações e aldeamentos e incentivo ao casamento interétnico, submetendo todos às leis civis que faziam sentido para as populações urbanas de Portugal. O propósito, especialmente na fronteira Oeste, era desencadear a nacionalização das terras e dos "naturais", não mais excluídos, mas sim abrangidos, assimilados pelo plano colonial.

Os relatos dos engenheiros demarcadores, naturalistas, capitães, em particular em Mato Grosso na segunda metade do século XVIII, contém todo um universo de representações passíveis de serem interpretadas enquanto fontes de manifestação dos planos e da cultura colonial, assim como das respostas pertinentes às mais diferentes etnias naia na tumultuada faixa de fronteira.

A perspectiva antropológica pode, por exemplo, iluminar as relações entre os portugueses e os índios habitantes tradicionais do Pantanal. Através dos relatos de Ricardo Franco de Almeida Serra e do governador Montenegro, é possível constatar que também os Guaicuru buscavam obstinadamente "pacificar" os portugueses. Seus relatos apontam para a complexidade daquelas relações, marcadas pelos confrontos étnico-culturais.

Uma das grandes dificuldades dos portugueses, na sua incansável tarefa de fundar aldeamentos, era justamente convencer os Guaicuru a tornarem-se agricultores, atividade que eles consideravam "menor", própria dos camaradas Guaná, capturados em guerras. As relações de dependência eram anteriores ao contato com os colonizadores e pautavam comportamento dos Guaicuru na relação com os portugueses, que estava convencidos do estereótipo do selvagem preguiçoso e, no caso desses, arrogante.

Os Guaicuru que surgiram nos relatos estavam em posição superior, senhores da situação, surpreendendo, confundindo os portugueses nas suas estratégias de aproximação. Eles eram vaidosos e ridiculamente soberbos, nos dizeres de Ricardo Franco em seu relato publicado em 1872; desprezavam os demais índios e viam-se como heróis e fidalgos, mostrando sem demora as dificuldades em submetê-los aos planos de colonização.

O trabalho de Gilberto Brizola dos Santosnrevela bem os confrontos culturais e a dimensão das dificuldades encontradas para a sua submissão. Os índios chamavam de "português" qualquer um dos seus, quando queriam fazer chacotas, ironias com ele, e chamavam de "guaicuru" o português alvo de seus elogios. Os relatos de Ricardo Franco exibem os desencontros, o choque de códigos culturais presente nas relações cotidianas, empurrando para o plano do desejo a "civilização".

$A$ Coroa havia dado ordens para aldear os Guaicuru, promovendo o casamento com portugueses, a prática da agricultura e da pecuária de pequenos animais, recebendo em troca certos bens como tecidos e ferramentas. Depois de uma "longa conferência entre eles, o chefe, ao relatar o resultado da discussão, respondeu que os Guaicuru aceitavam a proposta dos portugueses mas queriam saber 
quantos escravos receberiam para fazer as roças e as casas, pois não eram "cativos". Todos queriam as casas, mas que fossem fazê-las os portugueses, pois a madeira da construção era muito dura, poderia machucar seus ombros. Todos também poderiam aceitar as mulheres portuguesas, mas não aceitavam a imposição de não poder separar-se delas. Isso não admitiam, como não admitiam também batizar-se para contrair os matrimônios.

Ao convidar as lideranças Guaicuru para que viessem a Cuiabá buscar alguns "mimos" (ferramentas, panos) para que produzissem roças e criassem algum gado, o português recebeu desconsertado a resposta de que só os Guaná "se empregavam gostosamente por interesse nesse trabalho". Quando dona Catarina, que pertencia à nobreza Guaicuru, separou-se do marido, o comandante do Forte Coimbra "colocou seus officiais à disposição para o novo casamento, mas todos foram rejeitados, por serem julgados inferiores. Quando aceitavam portugueses para casamentos, os Guaicuru davam-lhes fardão e bastão para torná-los capitães" (SANTOS, 2000). Os índios "gabavam-se" diariamente de que, apesar de serem os portugueses muito bravos, eles souberam amansá-los!

Era para amansar os portugueses que as mulheres Guaicuru vendiam seus favores sexuais. Diferente dos Guaná, que não escondiam as relações de suas mulheres com os colonizadores e até se orgulhavam), eles negavam, afirmando que elas o faziam "sem malícia".

A riqueza dos relatos de Ricardo Franco está na sua insistente busca por compreender o mundo dos Guaicuru, sua lógica, seus significados. Um ser supremo, o pássaro Carcará, havia dado vida ao primeiro homem, que recebera do criador a lança e o porrete para conquistar os outros povos e torná-los cativos, "pois sobre todas elas lhe dava domínio e senhorio". Só os Guaicuru "de origem" acreditavam naquela "pantunha", disse Ricardo Franco, embora no mesmo relato tenha registrado que os índios não matavam o carcará "por respeito ao pai comum" e por medo de desgraças, como o risco de cair do cavalo.

Esse verdadeiro diálogo (de surdos) cultural que envolvia as relações entre os portugueses e os índios constituiu uma história bastante particular de colonização, distante das simplificações historiográficas que veem nos índios unicamente vítimas passivas ou selvagens sanguinários, a atacar as rotas de comércio e as povoações, cruéis empecilhos à expansão colonial.

Hoje em dia, já é possível encontrar, pelos corredores calorentos da UFMT, alguns entusiasmados estudantes de graduação e pós-graduação debatendo a importância da École des Annales para sua formação de historiador, professores mestres e doutores encarregam-se de incluir a nossa UFMT na rota dos debates históricos atuais, afirmando sua identidade com a historiografia contemporânea.

Uma das mudanças mais sensíveis foi a assimilação do gosto pela liberdade nas escolhas dos objetos, tornada "vocação" da nova História Cultural. As visões conservadoras acerca de Mato Grosso no "período" colonial vão cedendo lugar para estudos sobre "representação", trabalhando com a construção de identidades e outras questões até hoje inerentes ao campo da Antropologia. Professores que jamais tiveram a perspectiva de fazer uma etnografia debatem-se com as leituras de Lévi Strauss, tentando sobreviver à sua Antropologia atemporal, muitas vezes inatingível para os não iniciados.

É um momento de grande instabilidade para todos nós, que transitamos pela vastidão das Ciências Humanas em uma universidade acostumada a consumir e repassar conhecimento mais do que produzi-lo. Aos salários baixos e à falta de prestígio junto aos governos, que sucateiam sistematicamente o ensino público, 
juntam-se as dificuldades inerentes às próprias áreas de conhecimento, que passam por reformulações profundas, obrigando os professores a minimamente situarem-se diante delas.

“Tudo é História!" - disse-me certa vez uma convicta mestre historiadora na UFMT, em uma tarde qualquer de reunião adiada - "até mesmo a Arqueologia e a Antropologia!" Isso soou aos meus ouvidos como uma saudável provocação, à qual resolvi responder com um olhar perscrutador, nos moldes do que faz James Clifford, observando pelas bordas, pelas margens da disciplina, as representações que vêm sendo construídas ou partilhadas sobre ela. A novidade é que aquela frase parecia ser a entrada definitiva da UFMT nos debates atuais da ciência e poderia, em tempos globais, ser ouvida aqui, em pleno sertão do Brasil, tanto quanto em Londres, Nova York ou Paris!

Em Mato Grosso, o antropólogo é hoje um misto de aliado e competidor, uma figura incômoda com a qual todos vêm-se na urgência de conviver, sob risco de serem rotulados de superados ou mal informados. E uma identidade que traz prestígio ao seu portador, principalmente diante de estudantes e da mídia, que têm uma visão extremamente folclorizada acerca desses seres estranhos (que estudam igualmente povos estranhos), que ninguém sabe muito bem o que são e o que fazem. Culturas e povos indígenas são abordados por sociólogos, assistentes sociais, estudantes de medicina, de comunicação, agrônomos, pedagogos, geólogos (!), geógrafos e historiadores que, às vezes, por selecionar os índios como objeto, identificam-se como fazendo etnohistória.

Os trabalhos que são aqui publicados estão inseridos na ebulição criativa que atinge - já não sem tempo - algumas áreas de conhecimento e de pesquisa na UFMT. Gilberto Brizola dos Santos, Ana Paula Lopes e Suelme Evangelista Fernandes são graduados em História. Este último é hoje professor universitário e mestrando do programa de pós-graduação do Departamento de História, sob orientação do Dr. Carlos Alberto Rosa. Os dois primeiros já foram professores substitutos do Departamento de Antropologia. Luiz Vicente da Silva Campos Filho é um etnoecólogo, mestre pelo Instituto de Biociências, e Marina Azem é médica.

O historiador Gilberto Brizola dos Santos, como já foi referido, estuda a visão dos portugueses colonizadores acerca dos Guaicuru, revelando novas possibilidades interpretativas. Os historiadores Suelme Evangelista Fernandes e Ana Paula de Oliveira Lopes interessam-se pela questão da dominação e da cultura portuguesa, na construção do território lusitano da região de fronteira. Luiz Vicente da Silva Campos Filho e Marina Azem exploram os registros de Alexandre Rodrigues Ferreira, um brasileiro formado em Portugal por Domingos Vandelli, naturalista italiano que, no século XVIII, introduziu os estudos científicos em Portugal, depois da reforma da Universidade de Coimbra, sob a orientação do Marquês de Pombal.

Alexandre Rodrigues Ferreira foi assistente de Vandelli no Palácio da Ajuda, em Lisboa, e em sua expedição pela Amazônia, a mando da coroa, fez registros preciosos sobre a abundância dos recursos da floresta, o manejo das espécies, que na época já era praticado pelos colonizadores, o conhecimento indígena e a importância das suas culturas para a sobrevivência dos novos povoadores. Seus diários fornecem dados sobre as enfermidades, os procedimentos terapêuticos, as epidemias, os ambientes insalubres, além dos recursos naturais utilizados como medicamentos. São relatos que permitem apreender as representações sobre as sociedades e o ambiente amazônico, tornando possível uma variedade de leituras etnográficas como, por exemplo, a resposta dos índios à escravidão a que eram submetidos na coleta dos produtos da floresta: para enganar o colonizador, eles 
usavam a "malícia" de pendurar as árvores de salsa ou queimar partes da planta (que facilmente se reproduzia), para que ela se extinguisse e assim "r455se extinguisse a perseguição para que eles a coletassem”.

Este único dado ilumina a compreensão da história da exploração colonial das espécies naturais da Amazônia e revela o "diálogo de surdos" que chegou a ser instalado, onde a agressão da exploração do conhecimento e da mão de obra indígena tinha como resposta a agressão do explorado à floresta, como uma estratégia de sobrevivência diante do desconhecimento do próprio explorador. Essa compreensão só é possível pelo caráter minucioso das descrições de Alexandre Rodrigues Ferreira e pela leitura etnográfica dos seus dados, fornecida pelo diálogo das várias áreas de conhecimento com a Antropologia.

Gilberto Brizola dos Santos, terminando seu contrato como professor-substituto do Departamento de Antropologia, prepara-se para cursar o mestrado em Antropologia e dar continuidade ao seu trabalho sobre as relações entre os portugueses e os índios Guaicuru no século XVIII. Ana Paula de Oliveira Lopes, Luiz Vicente da Silva Campos Filho e Marina Azem continuam trabalhando seus temas sob minha coordenação. Juntos temos um projeto de pesquisa em Portugal, que começou ainda em 1997, quando recebi um financiamento do CNPq (CNPq/CAPES, processo n. 450443/97) para trabalhar a documentação existente em arquivos históricos de Lisboa, Coimbra e Évora. Em novembro de 1999, a convite do Grupo de Trabalho do Ministério da Educação de Portugal para as Comemorações dos Descobrimentos, apresentei o trabalho "Memórias portuguesas sobre os selvagens: cultura e história em Mato Grosso no século XIX” no Congresso Portugal-Brasil: Memórias e Imaginários, na Fundação Calouste Gulbenkian, em Lisboa. Publicado em Portugal em 2000, nas atas do Congresso (ISBN 972-8186-665), esse trabalho já delineava os contornos da problemática que agora exploramos, no sentido da construção de uma história das relações étnicas, tendo como instrumento de reflexão não só os documentos oficiais, mas principalmente os registros portugueses, nas suas impressões, descrições, nos seus julgamentos pessoais e nas construções dos seus relatos históricos.

Nossa próxima publicação, em vias de financiamento através da lei estadual de incentivo à cultura, reúne trabalhos em torno da documentação existente na Casa da Ínsua, em Penalva do Castelo, em Portugal, em conjunto com o Instituto de Estudos Brasileiros da Universidade de Coimbra.

Ao dar continuidade à publicação do Departamento de Antropologia (Cadernos de Antropologia, Série Ensaios Antropológicos), reafirmamos nosso esforço coletivo para a consolidação da nossa área de conhecimento na UFMT, sem dúvida uma das mais produtivas, apesar de todos os obstáculos, de todas as limitações e da falta de estímulo constante, decorrentes da crise que atinge as instituições públicas de ensino e pesquisa do país.

Cuiabá, julho de 2002. 
$\mathrm{U}$ ma das principais mudanças no comportamento dos novos historiadores é a sua recusa à posição de detentores da palavra final acerca da verdade histórica, contida nos grandes temas consagrados da historiografia ocidental, ensinada nas salas de aulas por universos heterogêneos de professores.

Recorrer a Pierre Bourdieu tem sido sempre de grande utilidade para desvendar o emaranhado de relações sociais que se processa no interior de um determinado campo científico, no sentido da competição pela hegemonia na definição das verdades. $\mathrm{O}$ interesse que os temas e objetos de pesquisa despertam nos jovens estudantes e pesquisadores também é resultado da avaliação da possibilidade de acumular prestígio e distinção, pois aquilo que é percebido como "importante e interessante" na produção científica é, nos termos de Bourdieu (1983: 125), o que tem chance de ser reconhecido como importante e interessante aos olhos dos outros. Ao deslocar a discussão dos sistemas epistemológicos para uma sociologia do campo científico, ele mostra que o mundo da ciência não é "puro", mas existe como um campo social, como outro qualquer, com seus interesses, estratégias, lucros, sendo bem definido como um espaço de relações concorrenciais, onde o que está em jogo é o monopólio da autoridade.

A crise na hegemonia da história econômica obrigou os historiadores a rever seus paradigmas, especialmente a partir dos anos 80 , provocando a recente e forte ascensão dos estudos sobre as culturas, terreno palmilhado pelos antropólogos, que são reconhecidos pelo capital científico acumulado desde o século XIX, no estudo das sociedades não-ocidentais.

A própria Antropologia vê-se às voltas com o seu passado e convive hoje com os questionamentos provocados pelo movimento dos chamados "pós-modernos", ciosos da importância estratégica de não empurrar para baixo do tapete algumas novas "verdades" (e consolidar outras). Cardoso de Oliveira, em seu ensaio sobre as matrizes históricas da disciplina (1998), identifica heranças da hermenêutica3 na "desordem" operada pela nova Antropologia, que inovou na negação radical do discurso cientificista hegemônico do passado. Libertada da coerção da objetividade, dos paradigmas da "ordem", tomou sua forma socializada, "assumindose como intersubjetividade"; o indivíduo, "igualmente liberado das tentações do psicologismo, toma a sua forma personalizada (portanto o indivíduo socializado) e não teme assumir a sua individualidade", e a história assume-se como historicidade, livre das "peias naturalistas que a tornavam totalmente exterior ao sujeito cognoscente".

A chamada Antropologia "tradicional" (norteada pelos paradigmas da Escola racionalista francesa e o estrutural-funcionalismo da Escola britânica) não exclui, mas "domesticou" aqueles três elementos que ameaçavam a integridade do campo da disciplina.

Negar a proeminência da subjetividade, do indivíduo ou da história é ter esses elementos ao menos sob controle. É assim que se tomarmos os paradigmas da ordem um a

\footnotetext{
3 "O que se verifica é uma verdadeira dispersão de influências nessa Antropologia que se pretende nova. Nem a "hermenêutica ontológica" de Heidegger e Gadamer, nem a "hermenêutica metódica" de Betti ou de Hirsch, nem a "hermenêutica fenomenológica" de Ricoeur (e muito menos a "hermenêutica clássica" de Schleiermacher e Dilthey) dominam aquilo que prefiro chamar de "consciência hermenêutica" na Antropologia "pós-moderna". Não obstante, não se está afirmando com isso que essa subjetivação na Antropologia não envolva em si mesmo uma certa controvérsia. Prefiro, por hora, retê-la como uma expressão nativa, originária no interior da comunidade" (CARDOSO DE OLIVEIRA, 1998: 97).
} 
um, observaremos que enquanto o paradigma racionalista, pelo menos em sua primeira fase (pré-estruturalista) passa relativamente incólume pela ameaça de ser perturbado pelo tempo, praticamente ignorado em quanto tempo histórico, o paradigma estrutural-funcionalista reage primeiramente por uma crítica à questão da causalidade e secundariamente, como consequência pela exclusão da história do horizonte da disciplina (...) História que passa a ser um marcador da desordem e cuja erupção no interior da estrutura social só poderia ser um complicador na capacidade explicativa da Antropologia, especialmente quando investida da missão de vir a ser uma verdadeira "ciência natural da sociedade". (CARDOSO DE OLIVEIRA, 1998: 94)

Na nova Antropologia, esses três elementos passaram a ser repensados e reformulados, e ela lança sobre si mesma um olhar de estranhamento antes destinado apenas ao Outro, diferente e distante. Ela faz a crítica radical às suas raízes iluministas, colocando sobre suspeição o poder absoluto da razão e da ciência (que tiveram em Nietzsche o seu ancestral), rejeitando as grandes narrativas, a metateoria ou metadiscurso. O que presenciamos em nossos dias é um certo "anarquismo epistemológico", com ênfase nas "pequenas narrativas", expressivos particularmente no universo da Antropologia Interpretativa.

Dentre os seus autores mais radicais estão os americanos George Marcus e Michel Fischer, com o seu "damn book", Writing Culture, onde a disciplina chegou a assumir a condição não de ciência, mas de "crítica cultural". Para George Marcus, comemorando os dez anos da obra, em artigo de 1998 na revista portuguesa Etnográfica:

This volume [Writing Culture] has served several functions in the curse of this trend.
For scholars who wanted to further develop and work from the critique of disciplines,
it was on of the texts to get beyond, by critiquing the critique, so to speak, by establish-
ing one's own position by setting oneself often within the critical project that Writing
Culture represented, but against it specifically (...) For others, especially graduate stu-
dents facing dissertation committees, Writing Culture has served more sympathetically
as a kind of ironic legitimation for producing work against the authorities of disci-
plines, wich of course lean heaviest in the curse of career-marking graduate research
projects. (MARCUS, 1998: 5-6)

O pós do pós-moderno carrega um descontentamento com o entendimento acerca da história. Há, segundo Vincent Crapanzano (1991: 433), um certo prazer na impossibilidade de qualquer entendimento universal, qualquer verdade incontestável, qualquer argumento indefensável, qualquer autoridade final. Questionase as visões que se conheciam as experiências que alimentam um senso de continuidade, que selecionam e organizam eventos; questiona-se a adoção de um ponto apropriado e a autoridade que autoriza esse ponto. Deus está morto no mundo pós-modernista (mais uma vez é bom lembrar que Nietzsche é o herói). Não há uma fé em grandes narrativas, que legitimam a ciência, nem em outras visões totalizadoras do mundo.

A despeito de serem vagas, generalizantes, contraditórias, as definições sobre o que é pós moderno enfatizam a flexibilidade do seu discurso, que embaralha e torna inseparáveis o sujeito e o seu objeto. Somos pegos, como diz Crapanzano (1991), na arbitrariedade dos signos, onde já não há mais referentes, constrangidos por gramáticas de estilo ou narrativas: "O pós-moderno deve muito a Saussure".

A Antropologia pós-moderna de Clifford Geertz tem exercido sua hegemonia entre antropólogos e historiadores, servindo como uma referência no espaço do diálogo multidisciplinar do estudo das culturas. Seu conceito é semiótico e sua 
antropologia identifica-se não como sendo ciência experimental, em busca de leis, mas uma ciência interpretativa, em busca do significado4.

O historiador Robert Darnton, em uma entrevista a pesquisadores brasileiros (SCHWARCZ, 1996), assim relatou o encontro da sua História das Mentalidades com a Antropologia Interpretativa de Clifford Geertz, o que sugere que coincidências mais do que embates têm produzido as multidisciplinariedades, desde os anos 6o, na Universidade de Princeton:

Logo que conheci Geertz, o que nos uniu foi a simpatia, como no caso de [Michel] Vovelle e [Philippe] Ariès. A palavra simpatia é estranha, mas explica nossa relação. Na verdade, Geertz é um sujeito difícil: fala mal, se coça o tempo todo, tem uma barba imensa e uma inteligência notável. Conhece profundamente matemática, jazz: gosta de esportes sem ser esportista; sabe tudo sobre o Corão (e lê em árabe); sobre linguística e tem uma formação literária impressionante. Isso sem falar dos seus conhecimentos sobre a Indonésia e a África do Sul, seus campos de pesquisa. É o homem mais culto e inteligente que causa medo aos outros. Quando falamos com ele temos a impressão de sermos imbecis! E eu, porém, apesar de "imbecis", sinto-me bem com ele e entre nós desenvolveu-se uma grande amizade. Falamos como irmão. Ele é meu irmão mais velho - já que completou setenta anos - e somos muito ligados.

Em 1970, Geertz perguntou-me o que eu fazia em História. Contei a ele sobre minha ligação com a história das mentalidades e ele me disse: "Isso parece antropologia!!! Nós dois fazemos a mesma coisa." Eu contei então, que queria estudar a vida intelectual, mas não a dos não intelectuais, e ele me disse que isso também era antropologia.

Libertado da identificação superada com a História das mentalidades (fruto de um "trabalho de ocasião" que, se pudesse, "refaria"), hoje o que ele faz é História Cultural, de uma perspectiva diferente do seu colega de doutorado em Oxford, Roger Chartier, ao dar ênfase à sua influência antropológica:

História cultural é buscar entender a alteridade de outros universos culturais, a organização simbólica do mundo. E é por isso mesmo que para mim uma história cultural é uma História antropológica. É por isso que insisto no que temos em comum. É por isso que Chartier e eu podemos ser definidos como dois historiadores do livro. A diferença é que Chartier privilegia a recepção e eu pesquiso sobretudo a produção. Chartier não faz um trabalho documental e de arquivo como faço. (...) Essa é talvez uma questão de gosto, só que no meu caso eu peguei esse gosto pelo trabalho de campo e no caso da história, pela relevância da volta às fontes.

(...) Não concordo com a noção de símbolos utilizada por Chartier. Na minha opinião ele não entendeu ou não trabalhou com a antropologia simbólica. A noção de símbolo que uso não é original. Eu adaptei da antropologia (...) todo símbolo é multivocal e polifônico: um "triquestroques" ritual (ritual punning) (...) sincronia e diacronia aparecem ao mesmo tempo.

Chartier não compreendeu isso. Símbolo não é um valor; a explicação simbólica é sempre mais complexa porque é relativa e contextualizada. Mas esse é um detalhe, afinal Chartier não fez uma história antropológica. (SCHWARCZ, 1996)

No que ambos têm em comum, há a identidade de historiadores culturais e a rejeição a radicalidade dos pós-modernos como George Marcus e Michel Fischer. Embora aceitem sua visão geral, as "novas gerações" atacam sistematicamente Clifford Geertz e os resultados do seu trabalho: há neles conclusões e o "ditos" pós-modernos não contra esse tipo de conduta, "já que acreditam que a construção não é do indígena, mas sim do pesquisador; ou melhor é produto da perspectiva que o antropólogo adota”. Ainda na entrevista de 1996:

\footnotetext{
${ }_{4} \mathrm{Na}$ Antropologia, faz-se etnografia, diz Geertz (1989). Compreender o que é a prática da etnografia é começar a entender o que representa a análise antropológica como forma de conhecimento. O que define o empreendimento não é o método (não é como dizem os livros, os manuais, onde fazer etnografia é estabelecer relações, selecionar informantes, transcrever textos, levantar genealogias, mapear campos, manter um diário...) mas sim o esforço intelectual de fazer uma descrição "densa". Nossos fatos, nossos dados, são na verdade nossa construção das construções de outras pessoas, explicamos explicações...O etnógrafo tem diante de si uma multiplicidade de estruturas conceituais, complexas, que se sobrepõem, amarradas entre si, simultaneamente estranhas, irregulares, implícitas, que ele tem que apreender e apresentar. É como ler um manuscrito estranho, desbotado, cheio de subentendidos. Incoerências... mas "exemplos transitórios de comportamentos modelados".
} 


\begin{abstract}
Dessa maneira, o antropólogo parece ser mais importante do que o seu próprio objeto. Trata-se de uma postura tão complicada, que acaba inviabilizando a possibilidade de entendermos outros mundos simbólicos que não o nosso. Chegamos a uma fase, para utilizar uma expressão que gosto muito, de "epistemological glitters", em que todos estão sendo consumidos por esta angústia: ficam debatendo apenas entre si e acabam concluindo que seu trabalho com o "outro" não é mais possível. Sahlins e Geertz não aceitam a postura dessa nova geração que, por sua vez, os colocou um pouco à margem. (SCHWARCZ, 1996)
\end{abstract}

Darnton teve aí uma ocasião especial para exibir clivagens tanto entre os historiadores quanto entre os antropólogos, abrigados por esse enorme guardachuva que são os estudos das culturas. Geertz poderia bem ser definido como uma espécie de personagem mítico fundador, um pai, um herói mítico original, criticado e enaltecido pelos seus herdeiros.

A importância da sua influência e o incômodo que ela ainda causa só não superam a inquietante e "rejuvenescedora" Antropologia Histórica de Marshall Sahlins, tanto entre os antropólogos como entre os novos historiadores.

Sendo a história a realização, na sociedade, dos recursos que um povo põe em jogo para sua sobrevivência, para Marshall Sahlins, o grande desafio da Antropologia Histórica não é meramente saber como a cultura ordena os eventos históricos, mas saber como, nesse processo, a cultura é reordenação, ou seja: "como é a reprodução de uma estrutura se torna a sua transformação?”

Embora reconheça a importância da herança de Saussure, ele questiona a noção de linguagem como estrutura autônoma, argumento fatal da Antropologia Estrutural. Na perspectiva do sistema de signos, as mudanças são fortuitas, e a noção de sistema consiste no modo como esses materiais históricos são inter-relacionados, em qualquer tempo ou qualquer estado da linguagem. Nessa perspectiva (na perspectiva dos "paradigmas da ordem" discutidos por Roberto Cardoso de Oliveira) a história é excluída da análise estrutural, uma vez que ela é feita na sala. Aplicada ao campo da Antropologia, o que se perde aí não é meramente a história, a mudança, mas a prática, a ação humana no mundo, e Sahlins rejeita esse estruturalismo, pois o que se perde aí é o que a Antropologia tem de mais valioso. Trazido para ela com essas limitações teóricas, o estruturalismo mantém à história a distância, eu medo é o de colocar o sistema em risco.

Em seu consagrado Historical Metaphors and Mithical Realities (1981) o que Sahlins busca é a explicação teórica para determinadas ocorrências históricas. Suas ideias sobre a história são construídas através de acontecimentos concretos, demonstrativos, que tem a ver com a reação cultural dos índios havaianos para uma circunstância colocada pelo aparecimento do famoso capitão Cook e, posteriormente, o aparecimento de colonizadores europeus, missionários e comerciantes.

Ele se propõe a ver "a história na confrontação das culturas", no confronto das estruturas de significância para, assim, desvendar as circunstâncias "exóticas" da história do povo das distantes ilhas do Havaí. Tais circunstâncias envolveram as relações entre o navegador britânico, capitão Cook e os índios havaianos, no final do século XVIII e que, surpreendentemente, acabaram por levar ao seu assassinato ritual5.

\footnotetext{
5 Recebido como um deus, que chegava do além-mar, da morada espiritual dos chefes e deuses havaianos, o capitão Cook foi "vítima da interação de categorias culturais - suas e dos próprios nativos - que o levou a perigosos "riscos de referência”, até encontrar o seu trágico fim. Cook transgrediu, sem compreender, o status ritual que lhe fora concedido; foi nas palavras de Sahlins (1990:1 1), um "impacto fatal” produzido pela teoria havaiana de soberania divina com a prática britânica do imperialismo. O retorno de Cook pela segunda vez às ilhas coincidiu com o retorno anual do deus Lono e o tratamento recebido correspondeu à sequência ritual do festival de Makahiki, onde o deus retorna para fertilizar e reivindicar a terra, sendo morto por um chefe poderoso, no culto sacrificial de Ku. A fatalidade da morte de Cook foi a "imagem
} 
Apoiado na concepção de que as diferentes ordens culturais têm os seus modelos próprios de ação, de consciência, de determinação histórica - as suas próprias práticas históricas - Sahlins voltou-se também para o exemplo dos fiji, no século XIX, em suas relações com os missionários metodistas. Ele mostra que a conversão para a religião de Jeová podia não ser apenas uma simples expressão da convicção dos convertidos.

Depois de mais de um século de conversão pelos missionários metodistas, os fiji ainda chamavam o cristianismo de "religião de Thakombau", o chefe da federação de Mbau, o poder dominante em Fiji no século XIX. Thakombau significou a conversão de mais de oito mil "fiéis regulares" e até mesmo os deuses, através dos seus sacerdotes, preparavam-se para o cristianismo, admitindo a verdade do deus estrangeiro. Para os fiji, "verdade é mana", indica "poder de fazer com que algo venha a existir, da mesma maneira que uma ação fracassada por falta de mana é uma mentira. Do chefe fiji para o missionário: "Verdade, tudo o que vem do país do homem branco é verdade; (...) mosquetes e a pólvora são verdade, sua religião também tem de ser verdade”. A extraordinária presença do europeu era, para os fiji, um fato social total, ao mesmo tempo religioso, político e econômico (SAHLINS, 1990: 65).

O que está em questão na "revigorante” Antropologia Histórica (ou História Antropológica) se Marshall Sahlins é o incômodo problema da relação entre estrutura e evento. Evento não só como um acontecimento característico de um fenômeno, mas como aquilo que "é dado como interpretação". Sua significância histórica só é adquirida quando ele é apropriado através de um esquema cultural. As categorias culturais que se realizam praticamente em um contexto histórico compõem a "estrutura da conjuntura", a estrutura tem uma diacronia interna.

São essas as razões do estímulo que seus estudos fornecem aos novos historiadores, que lutam para se contrapor a tradicional história econômica e social. Lynn Hunt (1992), ao apresentar o ensaio de Aletta Biersack na coletânea "A nova História Cultural", lembra que ela sugere uma certa "dose" de Marshall Sahlins, como sendo salutar para futuras obras sobre a história da cultura, lembrando também que a própria reflexão antropológica tem visto seus paradigmas a partir dos postulados de Geertz, na direção da compreensão do significado.

Sahlins, por sua vez, não economiza críticas aos historiadores que, segundo ele, desde há muito dedicam-se à discussão do que seria a historiografia! Correta”, a história das elites ou a vida das comunidades. A "nova história", ele diz (1994: 60), é de" inspiração populista", por vezes "cliente das ciências sociais e se volta para questões como a das estruturas inconscientes, mentalidades coletivas e tendências econômicas gerais". Sua tendência a ser "populista" vem da relevância dada às ideias de que a história é culturalmente construída de baixo para cima.

É preciso estar sempre atento para relembrar os ensinamentos de Pierre Bourdieu: uma discussão epistemológica jamais é apenas, unicamente, uma discussão epistemológica. Ela tem também o seu caráter político, inserida na disputa entre os concorrentes pela hegemonia das verdades cientificas. Cada qual mobiliza o seu capital intelectual simbólico acumulado, a partir da posição privilegiada em que se encontra no campo de forças, de disputas.

Em O beijo de Lamourette (1990: 14), Darnton diz que os historiadores estão sempre ombro a ombro com os mistérios, 'a insondável estranheza da vida entre 
os mortos", e voltam desse mundo como "missionários que partiram para conquistar culturas estrangeiras e agora retornam convertidos, rendidos à alteridade dos outros".

Um dos principais expoentes dessa história da "classe baixa" é Thompson, um precursor notável entre os historiadores de influência marxista - com o seu famoso The Making the English Working Class - na construção de um modelo de referência em como escrever uma história social e cultural, seu livro mais recente, Customs in Common (1991), continua voltado para o estudo da cultura dos trabalhadores, discutindo como os costumes se manifestaram ao longo do século XVIII e parte do XIX.

Em um de seus ensaios, $A$ Venda de Esposas, Thompson afirma que a história dessa prática "tão bárbara", na Inglaterra poderia ser descrita como amnésia, mais do que memória, e folcloristas do passado preferiram pensar em "resíduos pagãos", ignorância "apatetada" e brutal da população rural, sendo a venda considerada não mais do que uma transação comercial, a mulher inglesa leiloada como um animal, Ele questiona esse estereótipo, depois de dedicar- se por muitos à coleta de dados sobre as "vendas rituais", desde o final da década de 60 e durante toda a década de 70 .

Ele já tinha uns 300 casos em que suas fichas e adiava a publicação das conclusões, quando foi surpreendido por um novo estudo etnográfico sobre o mesmo tema, tornando sua pesquisa, segundo suas palavras (1998: 307), "ultrapassada" pelo trabalho de um antropólogo:

\begin{abstract}
O Estudo etnográfico do sr. Manefee foi realizado como dissertação junto ao Departamento de Antropologia Social da Universidade de Oxford, e o assunto talvez tenha chegado ao conhecimento desse departamento quando dei uma palestra sobre o tema num de seus seminários. Não podia reivindicar direitos autorais(...)minha primeira intenção era despertar interesse histórico e antropológico. Ainda assim, minha primeira reação foi considerar que meu trabalho se torna redundante pela ação de terceiros. $\mathrm{O}$ sr. Manefee investigara o tema com grande diligência; pesquisara em muitas bibliotecas e repartições de registros civis; reunira material muito curioso e às vezes relevante; e ultrapassara minhas próprias contas, com um apêndice de 387 casos. Além disso, ele partilhava minha definição do ritual (...). Com um pouco de tristeza ...deixei meu ensaio de lado.
\end{abstract}

Se ele retomou os estudos, apresentando seu ensaio tão tarde para o público, foi porque não achou depois que ambos tivessem se repetido as que as investigações dessem conta das mesmas questões, pois Menefee:

\footnotetext{
escreveu o texto como aprendiz de etnógrafo, e seu conhecimento da história social britânica e de suas disciplinas era "básico", tendo "pouco discernimento do contexto social, poucos critérios para distinguir entre a evidência confiável e a adulterada, e seus exemplos fascinantes aparecem no meio de uma mistura de material irrelevante e interpretações contraditórias.
}

No seu protesto e de certa forma no seu desabafo, na sua denúncia, o reconhecido historiador Thompson partilha os sinais dos novos tempos, onde o autor não se esconde do seu leitor e revela aspectos mais "subjetivos" das suas obras, até há bem pouco tempo escondidos nas entrelinhas das apresentações ou introduções dos estudos consagrados. Um assunto tão terreno como a competição pelos novos objetos ultrapassa as fronteiras do próprio campo de conhecimento e coloca em competição, em confronto, pesquisadores que até então debatiam exclusivamente com seus pares.

Esse caso de competição pelo mesmo objeto, envolvendo um atrevido iniciante nas artes da Antropologia e um historiador consagrado, revela que se há pontos de contato entre as disciplinas, há também os impasses. Se há casamentos 
há também divórcios, que se apresentam para todos nós como o nosso verdadeiro novo problema.

\section{A nova (velha) História Cultural francesa}

Os seminários e conferências de História Cultural na França, a partir dos anos 8o, impulsionaram a consolidação do seu espaço hegemônico no interior da disciplina. A influência da chamada Escola dos Anais fez seguidores fora atingindo especialmente abordagens norte americanas (HUNT, 1992).

As coletâneas publicadas a partir desses encontros são o retrato da multiplicidade, da diversidade genérica de historiadores da cultura. Dependendo das parcerias e dos conflitos, conjuntos multiformes de pesquisadores traçam suas tênues fronteiras de pertencimento, incluindo uns e excluindo outros.

Embora reconhecendo a influência da Antropologia, da Sociologia, da Literatura, da Linguística, um reconhecimento quase ritual, a História Cultural faz parte da escola histórica francesa, da própria história da consolidação da elite intelectual da França, traçada desde os anos 20 com Marc Bloch e Lucien Febvre. Mesmo que suas ideias migrem, ela continua sendo um debate no interior (francês) da disciplina, em torno dos seus historiadores mais consagrados.

Na introdução da coletânea Pour une histoire culturelle, publicada na França em 1997 e em Portugal em 1998, Jean-Pierre Rioux rejeita a visão de que a nova História Cultural é uma moda passageira, uma "fórmula vazia e pretenciosa" (como teria dito Le Goff) ou "um complemento de alma por um tempo latência epistemológica”, estruturalistas. Com muito esforço, trata-se de dar conta de uma ambição, que é a reunião em torno de uma reflexão "plural", de ordem historiográfica e metodológica, diante da proliferação do adjetivo "cultural", presente na multiplicação de produções históricas atuais. Trata-se de trabalhar com ardor, com a ajuda das "disciplinas irmãs', a História religiosa, das artes medieval e moderna. É verdadeiramente, ele diz, uma historiografia filha do seu tempo, relacionada às mudanças de perspectiva presentes no final do século.

Rioux Acredita que hoje as confluências estão mais fortes, as contribuições muito ponderadas, e as experiências são suficientemente convincentes para a proposição de um “acordo’ acerca De uma definição programática e operacional entre seus pares. Tal definição privilegia a História Cultural como o estudo das "representações" geradas, expressas e transmitidas por grupos humanos. Nas palavras de Jean-Francois Sirinelli (RIOUX, 1998: 20):

\footnotetext{
Como é que os grupos imaginam ou representam o mundo que os rodeia? Um mundo figurado ou sublimado-pelas artes ou pela literatura-, mas também um mundo codificado - os valores, o lugar do trabalho e do lazer, a relação com os outros -, contornando - o divertimento-, pensando - pelas grandes construções intelectuais -, explicado pelas crenças e os sistemas religiosos ou profanos, e mesmo mitos -, um mundo legado, finalmente, pelas transmissões devido ao meio, à educação à instrução.
}

A vastidão da paisagem, a amplidão que a História Cultural abarca, exige explorações metódicas e uma convivência disciplinada com outros campos, em jamais perder sua "vocação" de escolher e livremente inventar o seu tema de estudo.

Georges Duby, em seu ensaio de 1969, publicado na referida coletânea, já afirmava que não havia mais na França, depois do esforço de seus percursos Marc Bloch e Lucien Febvre, um historiador digno desse nome que hesitasse em considerar a cultura como sendo pertinente ao seu próprio domínio. O sucesso fulminante das ciências sociais, da psicologia e da linguística - seu impulso, a revolução nos métodos, "a maneira como captaram o interesse de um largo público para 
se estabelecerem no centro da nossa própria cultura" - exigiram dos historiadores que eles se juntassem a esse "pelotão conquistador" de "jovens disciplinas" que, por seu vínculo mais estreito com a filosofia, se esquivam das mudanças históricas.

Em Elogio da Complexidade, Jean-François Sirinelli, um dos organizadores dos seminários que resultaram na coletânea, argumenta que, na sua difícil missão de exumar um passado abolido, o historiador é confrontado com a complexidade ao quadrado, pois a "realidade" que ele busca "reconstruir" nunca foi apreendida na sua "pureza cristalina" a História Cultural interveem porque a "realidade", passada na "peneirada consciência dos homens", era "simplesmente representação", sendo a função do historiador analisar e integrar esses fenômenos. O que houve foi um retorno ao "sujeito pensante e que age", depois da erosão dos paradigmas a partir dos anos 70 .

\begin{abstract}
O Cultural cujo suposto estatuto de superestrutura [no caso das posições intelectuais do marxismo] ou de vaga secreção de estruturas dissimuladas [o estruturalismo] estava isolado entre os objetos periféricos - por secundários ou derivados - do território do historiador, ganhou desde logo em densidade e em autonomia. Tanto mais que a mudança, na mesma época, de configuração historiográfica, com o impulso da antropologia histórica, funcionou no mesmo sentido. (SIRINELLI, 1998: 410)
\end{abstract}

A História Cultural foi uma conquista importante da chamada "escola histórica francesa" no final do século, sendo a sua presença um "fato adquirido". Mesmo entre os historiadores já consagrados, que produziram obras importantes quando a história ainda não se apresentava como "cultural”, como Georges Duby ou Jacques Le Goff. A História pensada em períodos (medieval, moderno) também se renovou com os ares culturais.

A história medieval, também estímulo para grandes êxitos historiográficos da escola histórica francesa no decorrer do último meio século, teve em contrapartida relações complexas, senão com a prática, pelo menos com o rótulo de história cultural, em virtude da força legitima da história religiosa no seu campo historiográfico (...). (SIRINELLI, 1998: 411)

Maurice Agulhon (em Mariana, objetivo de Cultura?) é um desses historiadores que nunca haviam decidido escrever História "cultural". Mas se algum perito em epistemologia ou história da História considerasse hoje que seu campo de investigação tem a ver com essa vertente, ele não iria contestar. E assim irá continuar, pois o essencial em História “não é preencher rubricas, merecer ou honrar etiquetas, mas trazer alguns novos conhecimentos e produzir reflexões que possam ter, de tempos a tempos, valor de explicação" (AGULHON, 1998: 112). Seu ensaio acerca das representações culturais em torno de Mariana, a deusa símbolo da República francesa, inscreveu- se nessa nova busca de conhecimento, quando ele ainda via - se às voltas com a história das "mentalidades". Nas suas palavras: "foi sob a rubrica mentalidades que me recrutaram quando um princípio de notoriedade me permitiu ser recrutável” (AGULHON, 1997: 112).

A deusa Mariana é uma singularidade essencialmente francesa, explicável no passado quando a França era uma ilha republicana na Europa monárquica. Não nem havendo reis nem imperadores, a figuração do Estado com abstração faz-se através de uma alegoria feminina, emprestada da tradição greco-latina. E Agulhon (já sob influência dos novos ares culturais) deu-se conta de que Mariana não teve "irmãs" além-fronteiras! Os americanos," tão bons republicanos" quanto os franceses, não conheceram nenhum símbolo equivalente a Mariana e não fizeram tantas estátuas e retratos do Estado republicano como eles. 
Com historiador, ele explica essa diferença através da história, acreditando que "está nela uma grande parte da verdade":

\begin{abstract}
O civismo americano exprime-se mais pela veneração dos "país fundadores" (Washington, Franklin, Jefferson, etc) ligada com a que se ligada com a que se tem pelos presentes mais notáveis (Lincoln). É que a República americana tem "país fundadores" apresentáveis! A nossa República francesa não tem: os heróis da nossa revolução ou se saltaram contra ela (Mirabeau La Fayette), ou bateram- se contra eles (Danton, Robespierre), ou então voltaram à monarquia (Napoleão). Como venerá-los? (AGULHON, 1998: 119)
\end{abstract}

Não seria então, por isso que, na falta de pais fundadores honrados, tem os franceses que honrar a República em sua abstração anônima? - pergunta-se Agulhon. Mariana teria sido uma resposta (tipicamente) francesa não só como uma reação aos reis, mas também por causa dos heróis, contra eles. A República americana nasceu com a própria nação americana, sendo essa uma razão plausível para que a imagem da República na França seja "colorida”, apaixonada, enquanto que "lá, além-mar, calma na serenidade da evidência". A "análise dos símbolos" é uma das vias existentes para entender e explicar a contraditória República francesa, sua sociedade "complexa, talvez mais que outras".

A História Cultural francesa parece passar incólume a todo o conflito que atinge a Antropologia interpretativa contemporânea, "pós-moderna", acerca da representatividade da escrita etnográfica, onde o pesquisador não estranho apenas o "Outro", mas também a si mesmo, questionando o estatuto da sua verdade. Ao reconhecer a Antropologia como sua "vizinha", apropria-se de seus objetivos tradicionais e fazer uma incorporação ritualística (uma espécie de canibalismo simbólico...) dos seus conceitos e noções. A História Cultural é um "assunto doméstico", pertinente à história intelectual de França, que o mundo "de fora" só tem a espreitar, a aprender.

\title{
Antropólogos na selva: história e etnologia... Mato Grosso!
}

Depois de fazer uma abordagem geral acerca da constituição do campo de relações entre antropólogos e historiadores, passando rapidamente pela busca obstinada de consolidação da hegemonia da História Cultural francesa, seria no mínimo útil e oportuna uma introdução à repercussão que esses debates encontram onde menos se esperava, onde eles teriam menos probabilidade de se encontrar: na selva!

A Universidade Federal de Mato Grosso nasceu em 1970, sob a orientação do regime militar, dedicada a ser um centro de produção cientificar sob o signo da "Universidade da Selva". Nada mais paradoxal, se considerarmos que a selva, ao menos no imaginário europeu, evoca a ideia de um lugar absolutamente vazio de ciências, a confirmação cabal da sua total impossibilidade, distante imensamente do seu nicho civilizado, pois ali o homem primitivo impera, na solidão da floresta. Como toda a natureza, um homem objetivo da curiosidade e do interesse de viajantes e cronistas, os precursores dos homens de ciência que historicamente fizeram de Mato Grosso o seu campo de estudo.

Dois ambientes abrigaram, desde o início, os estudos dos antropólogos e historiadores em Mato Grosso, na UFMT: o Departamento de História e o Museu Rondon. Nos anos 80, os antropólogos compunham circunstancialmente uma área dentro do Departamento de História e desenvolviam suas pesquisas etnológicas no Museu Rondon, que passaram a dirigir em 1981, quando ainda era um 
órgão suplementar da Coordenação de Cultura. Em 1990, a criação do Departamento de Antropologia desvinculou os antropólogos do Departamento de História, consolidando sua área de conhecimento, com uma produção diversificada em termos de metodologia e unificada em torno de seus objetos, voltados para o estudo das culturas e sociedades indígenas.

Foi na área de Antropologia que os estudos de Etnohistória encontraram seus primeiros desdobramentos, através da participação de pesquisadores visitantes no Museu Rondon, financiados pelo CNPq. Nos anos 80, a antropóloga Denise Maldi, que faleceu precocemente em 1996, foi sem dúvida a sua grande precursora, interessada especificamente em fazer reflexões históricas em uma perspectiva etnográfica, quando ainda os historiadores recusavam- se a faze- lá, abarcando o seu universo infindável de dados sobre os índios de Brasília, estudando a sociedade dos índios Pakaas-Novos, ela iniciou o seu diálogo com a área de História em 1983, com seu trabalho de conclusão de especialização ("Mato Grosso: História e Historiografia”, coordenado pelo historiador Luiz Rios Volpato), com o título Populações indígenas e a ocupação histórica de Rondônia.

É de 1987 o seu principal trabalho de reflexão teórica acerca da proposta de construção de uma Etnohistória do Vale do Guaporé, apresentado em um seminário na UFMT. Publicado em 1993, com o título A teia da memória, o trabalho inaugurou a Série Antropologia, a publicação do Departamento de Antropologia, quando ela havia assumido a sua chefia. Em 1989, publicou pela Vozes o seu livro Guardiães da Fronteira - Rio Guaporé, século XVIII, marcando sua contribuição substancial em termos de metodologia. Depois de sua morte foi publicado, em 1997, pela Revista de Antropologia da USP um de seus principais artigos: "De confederados a bárbaros: a representação da territorialidade e das fronteiras indígenas nos séculos XVIII e XIX”.

Em A Teia da memória, ela discutiu a construção de uma Etnohistória a partir dos problemas teóricos próprios do campo da Antropologia, que assumia como sendo a sua disciplina de formação. Uma discussão nunca esgotada, um cenário, que ela colocava para a localização de alguns temas, voltados para a historiografia em uma perspectiva antropológica. Traçou um panorama sobre os problemas teóricos concernentes à Etnohistória, abordando as propostas metodológicas, as tendências e as dificuldades de alguns trabalhos para, finalmente, fazer uma reflexão sobre o instrumento, o recurso imprescindível das "histórias de vida", apontando para o seu propósito maior, que estava voltado para os índios do vale do Guaporé.

Ela considerou que a História e a Etnologia guardam em comum uma semelhança de método, na medida em que ambas evidenciam a importância da interpretação, como nos ensinaram os antropólogos clássicos. Clifford Geertz consolidou a ênfase na interpretação a partir dos anos 70, retomando o conceito de cultura, que é há muito tempo um patrimônio dos estudos antropológicos (LARAIA, 1995). O etnógrafo debate-se com uma multiplicidade de estruturas conceituais, que se sobrepõem e que devem ser apreendidas e apresentadas. Sua apreensão é tão difícil quando fazer uma leitura de um manuscrito estranho, desbotado, incoerente, cheio de vazios, comentários tendenciosos, escrito com sinais não convencionais. Recorrendo a Marshall Sahlins, Denise Maldi lembra que o que distingue o homem é que ele vive de acordo com sistemas simbólicos: o que determina que os americanos não comam carne de cachorro e comam a carne de gado é perceptível aos sentidos tanto quanto o preço da carne; o que determina que os homens usem calças e as mulheres usem saias não tem necessariamente conexão com as caraterísticas físicas mas sim com o sistema simbólico, onde o que conta não é a 
natureza do objetivo em si mas o fato de que calças são produzidas para homens e saias para mulheres.

O que atrai os historiadores é justamente essa ideia, lembrando Roberto Darnton e a influência de Geertz nos seus estudos: uma História de cunho etnográfico tem como propósito tratar a chamada civilização ocidental da mesma maneira que os antropólogos tratam as chamadas culturas exóticas. Contos infantis, descrições, narrativas bizarras, arquivos curiosos, embora não sejam típicos do pensamento, no caso, do século XVIII, fornecem "maneiras de penetrar nele". "Conversar com os mortos", tarefa essencial do historiador, não é só indagações aos documentos, buscar os significados através dos símbolos, da exegese dos textos. Na perspectiva histórica, o "nativo" é o documento. Tal qual ocorre na Antropologia, em que a relação informante-etnográfico é dialógica, onde o etnográfico é o iniciante, como já discutiu James Clifford, a propósito da textualização e da exegese de um sistema cultural. A observação e o diálogo são mediatizados pela interpretação. Ao propor as questões, o etnógrafo se inclui no seu próprio empreendimento, ele é parte da condição da sua própria pesquisa, por isso nenhuma etnografia é definitiva ou definitivamente objetiva. A produção etnográfica tem sua própria historicidade.

Denise Maldi pergunta-se: a que se propõe, de fato, uma Etnohistória? Sua pertinência está na constatação de que os trabalhos existentes sobre Etnohistória estão longe de constituir um consenso. A questão do tempo é tratada na Antropologia Interpretativa através da sua interiorização, onde o pesquisador assume a sua condição histórica, renunciando à objetividade postulada pelas abordagens positivas. Ela recorre ao argumento de Hayden White de que "o elemento histórico é uma estrutura verbal em forma de discurso narrativo, que pretende ser um modelo das estruturas passadas", para aceitar que os mitos também o são, ressaltando a posição de Lévi-Strauss, para quem a "história mítica", ao trabalho com simbologias, não significa "irrealidades". Busca em Raimundo Panikkar a lembrança de que somente para o espírito ocidental é desconcertante não ver no mito a história, sendo o mito e a história maneiras de ver o horizonte da realidade. A forma como o tempo é percebido é cultural, o tempo cíclico e linear não necessariamente estão em oposição. Em suas palavras:

\footnotetext{
Portanto, o dado documental (que é uma narrativa) e a narrativa mítica podem ser considerados perspectivas concorrentes de investigação e não dimensões metafisicas apostas. Além disso, qualquer forma de narrativa atesta o caráter simbólico da consciência do tempo. O discurso mítico, que os antropólogos consideram uma forma privilegiada de pensar, pode sem dúvida ser utilizado como modelo. (MALDI, 1993: 14)
}

O falecimento prematuro de Denise Maldi, em 1996, interrompeu uma vida intensa e vibrante, quando ela oferecida o melhor de si, quase por finalizar sua tese de doutorado, amadurecendo suas reflexos que tomaram impulso nos anos 8o, É impossível não recordar sua satisfação ao ser convidada para participar do Congresso Internacional de Ciências Antropológicas e etnológicas no México, em $1993^{6}$, e para debater com Chiara Vangelista, da Universidade de Torino (Itália), no Congresso de Americanistas em Estocolmo, na Suécia, em 1995, interessada nos povos indígenas da região de fronteira. Seu livro Guardiões da Fronteira, quando ela ainda assinava Denise Maldi Meireles, foi uma das principais fontes de Vangelista, sobre as relações hispano-portuguesas no Norte de Mato Grosso nos séculos XVIII e XIX.

${ }^{6}$ Onde apresentou seu trabalho Território, Movimento e Fronteira: Dinâmica e estratégica Culturais entre os PakkasNovos, publicado pela EdUFMT em 1998. 
No seu último trabalho público, "De confederados a bárbaros: a representação da territorialidade e da fronteira indígenas nos séculos XVIII e XIX”, na Revista de Antropologia da USP (vol. 40, n. 2) em 1997, ela assim apresentou os seus propósitos:

\begin{abstract}
Este trabalho é um ensaio etnohistórico sobre a representação europeia da territorialidade e da fronteira indígena nos séculos XVIII e XIX. Orientada por uma preocupação com o diálogo entre a Antropologia e a História, procurei construir uma abordagem da territorialidade e da fronteira enquanto categorias culturais que refletem historicidades próprias, discutindo o funcionamento conceitual da representação a partir da sua formulação na "história cultural". Esta fundamentação implica uma ressonância básica entre o objeto e a forma como é percebido, já que têm que ser entendidos, em primeiro lugar, a partir da representação que a sociedade faz de si mesma e do outro, ou seja, como define a territorialidade e com quem define as suas fronteiras. (MALDI, 1987: 184)
\end{abstract}

Na UFMT, os desdobramentos dos estudos dos antropólogos em diálogo com a História, enquanto uma disciplina ou uma área de conhecimento, são pautados muitas vezes por, digamos, "necessidades imediatas", decorrentes de sua atuação na direção de uma Antropologia Aplicada ou Antropologia da Ação. Isso ocorre tanto no campo as saúdes quanto no da demarcação de terras, coco é caso do projeto ${ }^{7}$ para identificação e delimitação do território dos índios migueleños, em Rondônia, expulsos da região do rio São Miguel para a criação da Reserva Biológica do Guaporé. A documentação portuguesa sobre essa extensão região de fronteira fornece elementos fundamentais para a configuração atual dos territórios indígenas, pois são a memória que não raro falta aos grupos sobreviventes do massacre histórico nos últimos 300 anos.

Outro estudo que fez um investimento mais demorado no debate entre as duas disciplinas foi a tese de doutorado Índios de Rondon. Rondon e as linhas telegráficas na visão dos sobreviventes Waimare e Kaxiniti, grupos Paresi ${ }^{8}$, defendida em 1994, sob orientação de João Pacheco de Oliveira, um pesquisador que é uma referência obrigatória na discussão sobre Antropologia Histórica no Brasil9. Além de gerar outros estudos, publicado na coletânea do Departamento de Antropologia Modelos e Processos- ensaio de etnologia indígena ${ }^{10}$, organizada por Edir Pina de Barros, levou também à atuação na demarcação de territórios Paresi, como a identificação e delimitação da Área Indígena Estação Parecis, cujo relatório foi publicado na coletânea, também do departamento de Antropologia, Direitos Indígenas e Antropologia: Laudos Periciais em Mato Grosso ${ }^{11}$, organizada ainda por Danise Maldi.

Um novo projeto sobre a documentação portuguesa do século XVIII, contemplando os indígenas e o debate sobre a fronteira, teve impulso com a criação do curso de especialização Antropologia: Teorias e Métodos, oferecido pelo Departamento de Antropologia entre 1999 e 2000, tendo como consequência a criação

\footnotetext{
7 MACHADO, Maria Fátima Roberto. Proposta de estudo para reconhecimento étnico dos índios Migueleños, de Porto Martinho (Rondônia). Funai- Brasília, nov. 2001.

8 MACHADO, Maria Fátima Roberto. Programa de Pós-Graduação em Antropologia Social do Museu Nacional (UFRJ).

9 João Pacheco de Oliveira (1988) já discutiu como as relações étnicas se articulam em um regime tutelar, através do enfoque das relações entre os índios Ticuna e o SPI no Amazonas, dando conta de que certas figuras, certas formas de ação do indigenismo oficial são pensadas pelos índios segundo seus próprios códigos, adquirindo uma dimensão que é metodológica, e que é ,ela mesma, expressão dos modelos, das teorias tradicionais de mudança social. Na interação, cada evento, cada ação é resultado da combinação de diferentes referenciais, havendo sempre um jogo de possibilidades, uma diversidade de código em operação, condicionados tanto por, fatores quantos cultural. Ao falar em situação histórica, se refere ao conjunto de relações entre atores sociais, cuja unidade não é um pressuposto teórico que explique todos os fatos, mas algo a ser pesquisado, buscando no processo concreto de interação e de percepção dos diferentes atores. Ele se recusa a valorizar os modelos estruturais na sua construção metodológica, para enfatizar a noção de processo, 'onde normas, crenças e expectativas devem ser abordadas em uma análise genético, que as trate como fatos em constituição, e não como atualização simples de códigos anteriores" (PACHECO DE OLIVEIRA, 1999: 113).

${ }^{10}$ EdUFMT, Cuiabá, 1998.

${ }^{11}$ EdUFMT, Cuiabá, 1994. Ver também: MACHADO, Maria Fátima Roberto. "Ponte de Pedra: Mito, Histórias e Arqueologia”, Relatório Complementar de Impacto Ambiental, 1999 (mimeo).
} 
de um grupo de estudo, envolvendo pesquisadores oriundos de áreas diversas, como saúde, ciências agrárias, ciências humanas e sociais.

A origem da proposta de fazer leituras antropológicas da documentação portuguesa sobre Mato Grosso está no trabalho "Memórias portuguesas sobre os selvagens: cultura e história nas relações étnicas em Mato Grosso no século XIX"12, apresentado no Congresso Portugal-Brasil: Memórias e Imaginários, ocorrido em Lisboa, em 1999, e publicado em suas atas em 2000. Foi um dos trabalhos que levaram à aprovação e financiamento pela CAPES/CNPq, em 1997, uma pesquisa em arquivos portugueses (Lisboa, Coimbra e Évora) durante o primeiro semestre de 1997.

Seu objetivo foi a importância das memórias, dos testemunhos históricos, dos relatos de vida - biográficos e autobiográficos - para os estudos históricos sobre identidade e relações étnicas em situações sociais de mudança, de rupturas, de conflitos. São recursos que colocam em jogo não só a memória histórica do seu portador, mas também toda a reflexão que é feita sobre ele mesmo, na sua condição de ator, emprestando de Erving Goffman (1995) a noção de representação. Incluindo de modo amplo os relatos históricos, essa concepção acerca de construção de memória busca valorizar não só o seu caráter informativo, histórico, factual, mas também sua característica sociológica, como um instrumento de construção e reconstrução de identidades. Na concepção de Pierre Bourdieu (1996), fazer uma retrospecção de fatos passados é sempre fazer uma versão no momento presente, é estiliza - lós em uma linha imaginária, um caminho histórico linear, homogêneo e compreensível, onde taticamente certas coisas são retidas e outra são esquecidas.

Nesta perspectiva, a Notícia sobre a Província de Mato Grosso seguida d'um roteiro da viagem da sua Capital a São Paulo, do português Joaquim Ferreira Moutinho, que viveu nas primeiras décadas do Brasil republicano, sobre a constituição do povo e a contribuição das raças para a formação da nação brasileira. A memória de Moutinho registrou a "selvageria" do sertão mato-grossense, à espera do "estrangeiro civilizador". Com sua observação minuciosa, penetrou na mais íntimo dos seus costumes, descrevendo suas casas, vestes, danças, vida econômica, até mesmo seus hábitos mais secretos e o cheiro de seus corpos. Nos seus relatos, aflora sua identidade portuguesa, em contraste com uma concepção de mundo essencialmente colonizadora. Um estrangeiro que, ao naturalizar a selvageria do outro, opera uma revelação de si. Estrangeiro no sentido que é dado por Georg Simmel (1950), não como aquele estranho fugaz, que chega e logo parte, mas sim como Moutinho que, ao viver quase duas décadas em Cuiabá, casar-se e enviuvar-se, permaneceu no limiar entre próximo e distante, entre indiferente e envolvido, ao mesmo tempo pertencendo e confrontando a sociedade cuiabana. Foi a partir da sua condição privilegiada - comerciante, genro de um major e coletor de impostos - que ele contribuiu a sua suposta "objetividade". O foco do trabalho está centrado no seu olhar sobre nativos, o que interessa não é só o que ele diz, mas também como e de onde ele diz, revelando a sua própria perspectiva na compreensão dos fatos. ${ }^{13}$

\footnotetext{
12 MACHADO, Maria Fátima Roberto. Ministério da Educação (ISBN 972-8186-66-5), Lisboa, outubro de 200o. Vol. II. 13 A história mato-grossense contemporânea, não contemplada aqui neste ensaio, apresenta novas perspectivas no diálogo com a Antropologia, mas, como já discuti anteriormente (MACHADO, 2000), historiadores tradicionais mato-grossenses apresentam em suas produções uma visão empobrecedora na utilização dos dados históricos disponíveis sobre as populações indígenas, tanto nos arquivos quanto nas memorias. Em estudos sobre o século XVIII, seus olhares estão comprometidos com o interesse em focalizar a inserção do índio como mão- de-obra da economia "interna" da colônia, diante da sua "invisibilidade" nos enquadramentos mais amplos de Mato Grosso no sistema colonial português, que privilegiam o enfoque do trabalho escravo africano. Os povos, as sociedades indígenas são também estranhas massas humanas, que vagam ao longo dos trabalhos, aparecendo ora como bravos guerreiros (por bravamente," selvagemente "resistirem ao invasor), ora como índios "civilizados”, os "trabalhadores livres”. Em seu estudo enfocando o século XIX. Aleixo (1984)
} 
A história da vida é um recurso empregado na construção de etnohistórias, como também já lembrou Denise Maldi no mesmo ensaio “A teia de memória”. É sempre um relato, uma construção narrativa, que serve a diferentes interesses, havendo a necessidade de formação de uma consciência reflexiva, fazendo emergir a internação entre o eu e o mundo. $O$ enfoque biográfico e as histórias de vida são instrumentos para o conhecimento do universo social, considerando que elas são construções feitas a partir de circunstâncias provocadas pelo pesquisador. Em suas palavras (MALDI, 1993:24), "pela memória não somente é possível ter a oportunidade de recordar o passado, mas, de certa forma, revivê-lo. Este processo envolve sensações, sentimentos e consciência crítica. O relembrar é em si mesmo um momento de interpretação e, exatamente por isso, nenhum relato de vida pode ser como pertencendo apenas ao indivíduo. As possibilidades são imensas".

\section{Referências}

ALEIXO, L. H. G. Mato Grosso: Trabalho escravo e trabalho livre (1850-1888). Brasília: Ministério da Fazenda/Divisão de Documentação, 1984.

AGULHON, M. M. Objecto de "cultura"? In: RIOUX, J.P. \& SIRINELLI, J. F. (org.). Para uma História Cultural. Lisboa: Editorial Estampa, 1998.

ARRUDA, T. J.; SIQUEIRA, E. M. Mão-de-obra ao pé-da-obra: a presença do índio no processo produtivo do Brasil Colônia. Porto Alegre. Revista Leopoldianum, XI: 31, 1984.

BOURDIEU, P. “O campo científico”. In: ORTIZ, R. (org.). Pierre Bourdieu. Col. Sociologia. São Paulo: Ática, 1983.

BOURDIEU, P. L'illusion Biographique. Actes de la Recherche en Sciences Sociales, juin, 1986.

CARDOSO de OLIVEIRA, R. “Tempo e Tradição: interpretando a Antropologia”. In: Sobre o Pensamento Antropológico. Rio de Janeiro: Tempo Brasileiro, 1988.

CARDOSO de OLIVEIRA, R. “A categoria da (des) ordem e a pós-modernidade da Antropologia”. In: Sobre o Pensamento Antropológico. Rio de Janeiro: Tempo Brasileiro, 1988.

CRAPANZANO, V. On the Writing of Ethnography. Dialectical Anthropology, 2 (1), 1977.

CRAPANZANO, V. The Postmodern crisis: Discourse, Parody, Memory. Cultural Anthropology, 6 (4), 1991.

DARNTON, R. O beijo de Lamourette. São Paulo: Companhia das Letras, 1990.

DUBY, G. “A História Cultural”. In: RIOUX, J. P.; SIRINELLI, J. F. (orgs.). Para uma História Cultural. Lisboa: Editorial Estampa, 1998.

GEERTZ, C. A Interpretação das Culturas. Rio de Janeiro: LTC, 1989. 
GOFFMAN, E. A representação do eu na vida cotidiana. Rio de Janeiro: Vozes, 1985 .

HUNT, L. "História, Cultura e Texto. Apresentação”. In: HUNT, L. (org.). A Nova História Cultural. São Paulo: Martins Fontes, 1992.

LARAIA, R. de B. Cultura: Um conceito antropológico. 10 ed. Rio de Janeiro: Zahar, 1995.

MACHADO, M. F. R. Índios de Rondon. Rondon e as Linhas Telegráficas na visão dos sobreviventes Waimare e Caxíniti, grupos Paresi. Tese de doutorado apresentada ao PPGAS do Museu Nacional, UFRJ, Rio de Janeiro, 1994.

MACHADO, M. F. R. "Identificação e Delimitação da Área Indígena Estação Parecis”. In: MALDI, D. (org.). Direitos Indígenas é Antropologia: Laudos Periciais em Mato Grosso. Cuiabá: EdUFMT, 1994.

MACHADO, M. F. R. "Rondon e os Paresi: as representações indígenas sobre o amure etnógrafo". In: PINA de BARROS, E. (org.). Modelos e Processos: Ensaios de Etnologia Indígena. Cuiabá: EdUFMT, 1998.

MACHADO, M. F. R. "Memórias portuguesas sobre os selvagens: cultura e história nas relações étnicas em Mato Grosso no século XIX”. In: Actas do Congresso Luso-Brasileiro "Portugal: Memórias e Imaginários”. v. II. Lisboa, 2000.

MALDI, D. Populações indígenas e a ocupação histórica de Rondônia. Cuiabá: EDUFMT, 1984.

MALDI, D. Guardiães da Fronteira. Rio Guaporé, século XVIII. Rio de Janeiro: Vozes, 1989.

MALDI, D. A Teia da Memória. Proposta teórica para a construção de uma etnohistória. Série Antropologia, 1, 1993.

MALDI, D. De confederados a bárbaros: a representação da territorialidade e da fronteira indígenas nos séculos XVIII e XIX. Revista de Antropologia, 40 (2), 1997.

MALDI, D. “Território, Movimento e Fronteira: Dinâmica e estratégia cultural entre os Pakaas-Novos". In: PINA de BARROS, E. (org.). Modelos e Processos. Ensaios de Etnologia Indígena. Cuiabá: EDUFMT, 1998.

MARCUS, G. E. That Damn Book: Ten Years After Writing Culture. Revista Etnográfica, 2 (1), 1998.

MARCUS, G.; FISHER, M. M. J. Anthropology as Cultural critique. An experimental moment in the Human Sciences. Chicago: The University of Chicago Press, 1986.

PACHECO de OLIVEIRA, J. O nosso governo. Os Ticuna e o regime tutelar. São Paulo: Marco Zero, 1988.

PACHECO de OLIVEIRA, J. Ensaios em Antropologia Histórica. Rio de Janeiro: Editora da UFRJ, 1999.

RIOUX, J.P. “Um domínio e um olhar”. In: RIOUX, J. P.; SIRINELLI, J. F. (org.). Para uma História Cultural. Lisboa: Editorial Estampa, 1998.

SAHLINS, M. Historical metaphors and mytical realities. Structure in the early history of the Sandwich Island Kingdom. Oceania/Michigan: Association for Social Anthropology/The University of Michigan Press, 1981. 
SAHLINS, M. Ilhas de história. Rio de Janeiro: Zahar, 1990.

SCHWARCZ, Lilia K. M. Entrevista Com Robert Darnton. Boletim da Associação Brasileira de Antropologia, 26 (1): 7-11, 1996.

SIMMEL, G. "The Stranger". In: WOLF, K. H. (org.). The Sociology of George Simmel. The Free Press, 1950.

SIRINELLI, J. F. "Elogio da Complexidade". In: RIOUX, J. P.; SIRINELLI, J. F. (org.). Para uma História Cultural. Lisboa: Editorial Estampa, 1998.

THOMPSON, E. P. Costumes em comum. Estudos sobre a cultura popular tradicional. São Paulo: Companhia das Letras, 1998. 


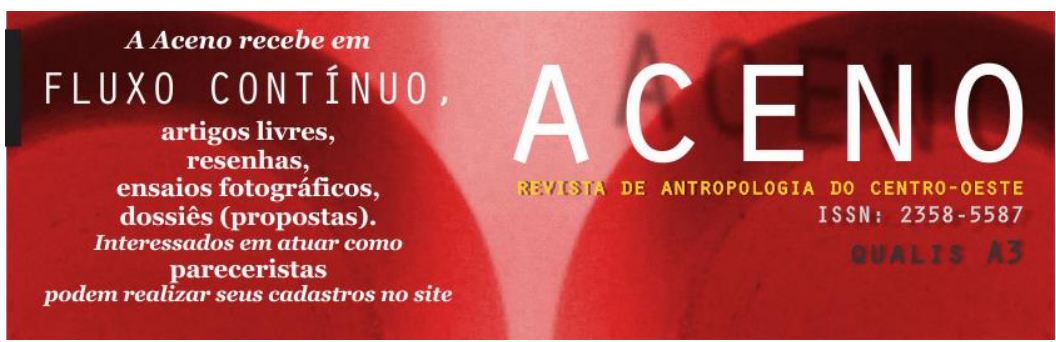

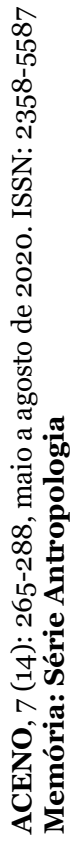

